\title{
General Psychiatry Mnemonics for diagnostic criteria of DSM V mental disorders: a scoping review
}

\author{
Pavan Kumar Kadiyala
}

To cite: Kadiyala PK. Mnemonics for diagnostic criteria of DSM $\checkmark$ mental disorders: a scoping review. General Psychiatry 2020;33:e100109. doi:10.1136/ gpsych-2019-100109

- Additional material is published online only. To view please visit the journal online (http://dx.doi.org/10.1136/ gpsych-2019-100109).

Received 27 June 2019 Revised 12 December 2019 Accepted 10 January 2020
D) Check for updates

(C) Author(s) (or their employer(s)) 2020. Re-use permitted under CC BY-NC. No commercial re-use. See rights and permissions. Published by BMJ.

Department of Psychiatry, Alluri Sitarama Raju Academy of Medical Sciences, Eluru, Andhra Pradesh, India

Correspondence to Dr Pavan Kumar Kadiyala; drkadiyala2@gmail.com

\section{ABSTRACT}

A multitude of psychiatric disorders have been described in classification systems like the Diagnostic and Statistical Manual of Mental Disorders Fifth Edition (DSM V). Diagnosing a specific mental disorder requires memorising specific symptom criteria, and their improper recall may result in misdiagnosis. Clinicians may use mnemonics, considering them as narratives or anecdotes of the diagnostic criteria. A scoping review of previously described mnemonics for DSM diagnostic criteria was carried out. An electronic search was done in PubMed, Google Scholar, Google Books and Google Search engine using a prespecified search strategy. Reference lists of relevant articles and chapters were hand searched to identify original and additional articles. Mnemonics retrieved from websites were manually searched in Google to identify published journal articles or chapters for the same mnemonics. Additionally, some mnemonics were developed, modified or added based on the author's knowledge. The comprehensive search identified 93 records (44 journal articles, 45 books and 4 websites) eligible for the review. Most of the mnemonics retrieved were related in some way to the disorder itself. They were listed under the heading of their respective disorders and indexed in the same order as in DSM V. The mnemonics that reflect a facet of their respective disorders were elaborated in detail.

\section{INTRODUCTION}

Mnemonics are specific devices for improving memory and have been used since classical times. It is unlikely that any of us come through life without relying on a mnemonic at some time or another. ${ }^{1}$ Mnemonics use cognitive cuing processes of organisation, elaboration and mental imagery during both learning and recall. ${ }^{2}$ Most mnemonics are categorised into acrostic sentences, acronyms, peg word, keyword, method of loci, rhymes or word play. Acrostic mnemonics are sentences in which the first letter of each word is the first letter of one of the things that need to be remembered. An acronym is a word created by using the first letter of each word of the information to be recalled. Mnemonics made by oneself are often the most useful. Often the sillier and more ridiculous the mnemonic is, the better one can remember it. ${ }^{23}$

Mnemonics as narratives or anecdotes are particularly useful in medicine, where it is often necessary to learn clusters of symptoms corresponding to a particular diagnosis. ${ }^{1}$ Reliable diagnoses are essential for treatment, research, documentation and epidemiological purposes. The current and Fifth Edition of the Diagnostic and Statistical Manual of Mental Disorders (DSM V) serves clinicians as a guide to identifying the criteria for the diagnosis of mental disorders. ${ }^{4}$ The current paper presents a scoping review of mnemonics available in recalling the DSM diagnostic criteria for mental disorders. Alongside, some mnemonics developed or modified by the author are also presented.

\section{METHOD}

This review aims to provide an overview or map the available mnemonics rather than to critically appraise or provide concrete guidance for their use in clinical practice. A method of scoping review was selected to summarise and disseminate the available mnemonics for DSM diagnostic criteria. ${ }^{5} 6$ The methodology for this scoping review was based on the framework outlined by Arksey and O'Malley and ensuing recommendations made by Levac et al. ${ }^{78}$ The review included the following four key phases: (1) defining the research question and selection criteria; (2) comprehensive search of the literature; (3) data extraction, and (4) collating, summarising and reporting the results.

\section{Research question and selection criteria}

This review was guided by the question, 'What are all the mnemonics available for remembering the DSM diagnostic criteria for mental disorders?' Mnemonics published in any way, whether journal articles or chapters in books or websites or presentations and those developed or modified by the author, 


\begin{tabular}{|c|c|c|}
\hline & Criteria & Result \\
\hline S & Sampling strategy & Comprehensive \\
\hline $\mathrm{T}$ & Type of study & Any kind of qualitative study \\
\hline$A$ & Approaches & $\begin{array}{l}\text { Electronic and citation } \\
\text { snowballing }\end{array}$ \\
\hline $\mathrm{R}$ & Range of years & $\begin{array}{l}\text { No restrictions to the beginning - } \\
\text { to the end of September } 2019\end{array}$ \\
\hline $\mathrm{L}$ & Limits & Language (English) \\
\hline I & $\begin{array}{l}\text { Inclusion and } \\
\text { exclusions }\end{array}$ & $\begin{array}{l}\text { Included all the articles published } \\
\text { in any way, whether in journals or } \\
\text { chapters in books or websites or } \\
\text { presentations }\end{array}$ \\
\hline $\mathrm{T}$ & Terms & $\begin{array}{l}\text { DSM, psychiatry, psychiatric, } \\
\text { mnemonic, mnemonics }\end{array}$ \\
\hline$E$ & Electronic sources & $\begin{array}{l}\text { PubMed, Google Scholar, Google } \\
\text { Books, Google Search engine }\end{array}$ \\
\hline
\end{tabular}

DSM, Diagnostic and Statistical Manual of Mental Disorders; STARLITE, Standards for Reporting Literature searches.

were included. Search for mnemonics was limited to the English language, with no date restrictions applied. No exclusion criteria were defined based on the publication type, as long as the article described original research.

\section{Comprehensive search of the literature}

Literature was searched systematically in an expansive manner. It allows search strategies to emerge as the research investigation takes shape and ensures that data collection efforts yield more than narrowly redundant data. ${ }^{9}$ Electronic searches were carried out using PubMed, Google Scholar and Google Books to locate the relevant mnemonics. A search was also done by the Google Search engine to identify grey literature. A decision was made to screen only the first 100 hits in Google Books and Google Search engine because it was believed that further screening was unlikely to yield many more relevant articles. ${ }^{10}$ Articles from Google Scholar were retrieved by using Publish or Perish software. ${ }^{11}$ The keywords used in various combinations were: ['DSM OR psychiatry OR psychiatric] AND [mnemonic OR mnemonics]'. Searches were completed in September 2019. The results of searches were entered into a bibliographic software program (Zotero) for the automatic removal of duplicates. ${ }^{12}$ The STARLITE (Standards for Reporting Literature searches) principles were used to report the literature search (table 1). ${ }^{13}$ The selection process was also presented in a flowchart (figure 1).

The titles and abstracts of all the articles, the content of chapters and websites retrieved by the initial searches were screened. Full-text articles of those deemed relevant were retrieved for subsequent review. Reference lists and secondary citations in relevant articles and chapters were hand searched to identify original and additional articles in a 'snowball' technique. ${ }^{14} 15$ The articles with no secondary references were taken as original sources of the mnemonics and cited the same. There was no appraisal of the quality of the records. Mnemonics taken from the journal articles and chapters in books were given higher preference as they may be peer reviewed or edited systematically. Mnemonics retrieved from websites were manually searched in Google to identify published literature (in the form of journal articles or chapters) for the same mnemonics. If multiple records with the same mnemonic were available, then the oldest published article was given preference.

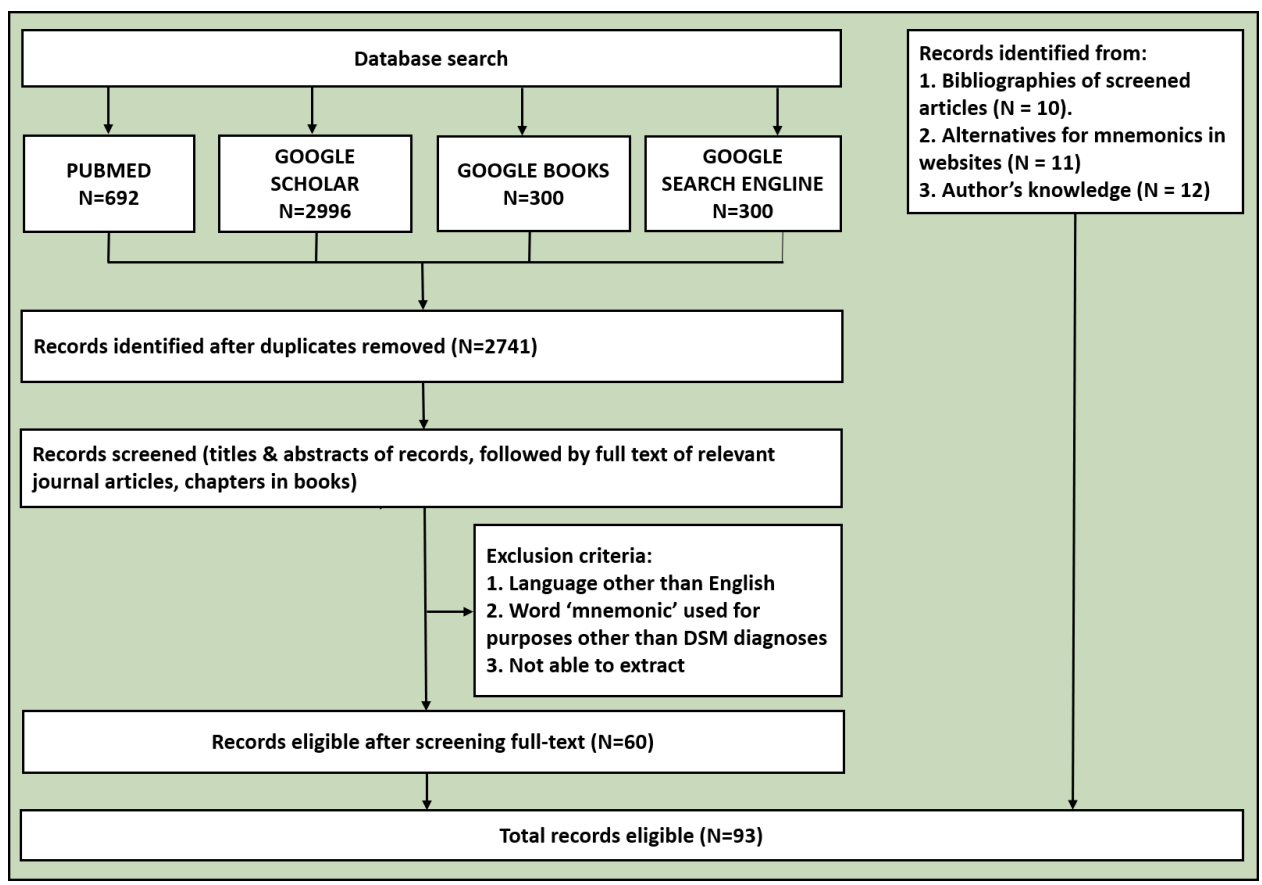

Figure 1 Flowchart of the study. DSM, Diagnostic and Statistical Manual of Mental Disorders. 


\section{Data extraction}

The data of mnemonics for diagnostic criteria were extracted by retrieving full-text articles or chapters of the books. The mnemonics from websites without published literature were retained by citing the website itself. Few articles and chapters were included based on the author's knowledge if mnemonics for any psychiatric disorder were not found by the search strategies applied. The authorship, year of publication, type and source of the articles were extracted and tabulated. The reasons that led to the development or collation of mnemonics were discussed.

\section{Collating, summarising and reporting the results}

The mnemonics were collated and summarised under the heading of each disorder. The disorders were indexed in the same order as in DSM V. Some mnemonics were modified or developed by the author. Those mnemonics that have no citation are the works of the author. Those mnemonics that reflect a facet of their respective disorders were elaborated in detail.

\section{RESULTS}

The comprehensive search identified 4288 records (PubMed 692, Google Scholar 2996, Google Books 300, Google Search engine 300). After the automatic removal of duplicates by software (Zotero), 2741 records were identified. Screening the titles and abstracts of these records, followed by the full text of relevant articles and chapters in books, retrieved 60 eligible records. Of these, 31 were journal articles and 25 were book chapters. The remaining four were websites without published literature. Eleven records were added when searched for published literature (of journal articles and chapters) for the mnemonics in websites. Ten records were retrieved from the reference lists of relevant articles. Twelve were added based on the author's knowledge. A total of 93 (44 journal articles, 45 books and 4 websites) were eligible for this review. The authorship, year of publication and type and source of the articles were tabulated and available in the online supplementary file 1 .

\section{Mnemonics for diagnostic criteria of DSM mental disorders Neurodevelopmental disorders \\ Intellectual disability}

'During development Intellects adapt by conceptual, social and practical support.'

1. Onset during developmental period.

2. Deficits in intellectual functions.

3. Deficits in adaptive functioning.

Severity defined on the basis of adaptive functioning in conceptual, social and practical domains that determine the level of supports required.

\section{Language disorder}

'Express or Comprehend words, sentences, discourses expected for age during development.'

1. Persistent deficits in expression and comprehension of language that include:
- Reduced word knowledge (vocabulary).

- Limited sentence structure.

- Impairments in discourse.

2. Below expected for age.

3. Onset in the early developmental period.

\section{Speech sound disorder}

'Sound limits communication during development.'

1. Persistent difficulty with speech sound.

2. Limits effective communication.

3. Onset in the early developmental period.

\section{Childhood-onset fluency disorder (stuttering)}

'Repeat or prolong or substitute the pauses or block repetitive tensions during development.'

1. Persistent disturbances in normal fluency and time patterning of speech, inappropriate for the individual's age and language skills. Frequent and marked occurrences of one (or more) of the following:

- Sound and syllable repetitions.

- Sound prolongations.

- Substituting problematic words (circumlocutions).

- Pauses within a word (broken words).

- Audible or silent blocking.

- Monosyllabic whole-word repetitions.

- Words produced with an excess of physical tension.

2. Onset in the early developmental period.

Social (pragmatic) communication disorder

'Understand social and contextual rules of conversation during development.'

A. Persistent difficulties in the social use of verbal and non-verbal communication as manifested by:

1. Difficulty understanding what is not explicitly stated or non-literal language.

2. Deficits in using communication for social purposes.

3. Disability to change communication to match context or the needs of the listener.

4. Difficulties following rules for conversation and storytelling.

B. Onset in the early developmental period.

\section{Autism spectrum disorder}

'Reciprocate, relate and communicate in social interactions; Restrict repetitive, rigid and unusual reactive behavior during developmental period.'

A. Persistent deficits in social communication and social interaction, manifested by:

1. Deficits in socioemotional reciprocity.

2. Deficits in developing, maintaining and understanding relationships.

3. Deficits in non-verbal communicative behaviours used for social interaction.

B. Behaviour or interests manifested by at least two of the following:

1. Highly restricted, fixated interests that are abnormal in intensity. 
2. Repetitive or stereotyped motor movements, use of objects, or speech.

3. Rigid adherence to routines, or ritualised patterns of verbal or non-verbal behaviour, insistence on sameness.

4. Hyper- or hypo-reactivity to sensory input or unusual interest in sensory aspects of the environment.

C. Onset in the early development period.

Other mnemonics for autism spectrum disorder (ASD; modified by the author) are:

1. AUTISTICS: ${ }^{16}$

Again and again (repetitive behaviour/speech)

Unusual (hyper or hypo) reactivity to sensory aspects

Toddlers (during early development)

Insistence on sameness, inflexible adherence to routines; Interests restricted and abnormal in intensity or focus

Socioemotional reciprocity deficits

To relate with others is a difficulty

Impairment in social, occupational or other functioning

Communication (non-verbal) poor for social interaction

Social communication below that expected for general development; that is, not due to intellectual disability

2. SCARE: ${ }^{17}$

Social relationships and reciprocity deficits

Communication for social interaction poor

Activities restricted, rigid and repetitive

Reactivity to sensory aspects hyper or hypo

Early onset

3. AUTISTIC PEOPLE ${ }^{18}$

Attention-deficit/hyperactivity disorder (ADHD)

Symptoms of inattention include (mnemonic: ATTEN-

TION): six or more

Attention difficulty

Trouble listening to others even when spoken directly

Tasks that require sustained mental effort are difficult

Easily distracted

Necessary things for tasks are lost

To finish what he/she starts is difficult

Is forgetful in daily activities

Organisational skills lacking

Not concerned about details or makes careless mistakes Symptoms of hyperactivity and impulsivity include (mnemonic: RUN FIDGET) (developed by the author based on other mnemonic: RUNS FASTT) ${ }^{19}$ : six or more

Runs, climbs or restless

Uninhibited in conversation

Not able to play quietly

Fidgets or squirms in seat

Interrupts or intrudes on others

Difficulty waiting his or her turn

Get going or acting as if driven by a motor

Evacuates seat unexpectedly

Talks excessively
Other mnemonics for ADHD

1. Inattentive symptoms: when the child is inattentive, CALL FOR FrEd (six of nine). Hyperactive-impulsive symptoms: with these symptoms, the child RUNS FASTT (six of nine).$^{19}$

2. Inattention: (mnemonic: SOLID); hyperactivity and impulsivity: (mnemonic: WORST FAIL). ${ }^{20}$

3. You'll need a MOAT around the classroom for the hyperactive child. Movement excess, Organisational problems, Attention problems, Talking impulsively. ${ }^{21}$

4. RAPID GIRL for symptoms of hyperactivity and impulsivity; DETAILS OFF for symptoms of inattention. ${ }^{22}$

5. CAN'T FOCUS? For inattentive subtype, DO I FIDGET? For hyperactive/impulsive subtype. The seven I's of ADHD combined type. ${ }^{23}$

Schizophrenia spectrum and other psychotic disorders

Delusional disorder: 'DeluSIONAL'

Delusion/s

Schizophrenia A criteria not met

Impairment of functioning is absent

Odd or bizarre behaviour absent

Not due to substance or another medical condition

Absence of mood episodes and if occurred are brief relative to the duration of delusional periods

Lasts 1 month or more

Another mnemonic for the delusional disorder is ' $\mathrm{NO}$ FAME', ${ }^{24}$

\section{Brief psychotic disorder}

'HalDol disorganizes speech and behavior in cat for at least 1 day but less than 1 month' ( $\geq 1$; at least one in first three).

A. Presence of one (or more) of the following, with at least one must be 1,2 or 3 :

1. Hallucinations.

2. Delusions.

3. Disorganised speech.

4. Disorganised behaviour including catatonia.

B. Duration for at least $\mathbf{1}$ day but less than 1 month.

\section{Schizophreniform disorder}

HalDol disorganises speech and behaviour in cat negatively for at least 1 month but less than 6 months (two of five; at least one from first three).

A. Two (or more) of the following, with at least one must be 1,2 or 3 :

1. Hallucinations.

2. Delusions.

3. Disorganised speech.

4. Disorganised behaviour including catatonia.

5. Negative symptoms.

B. Duration for at least $\mathbf{1}$ month but less than 6 months.

\section{Schizophrenia}

'HalDol disorganizes speech \& behavior in cat negatively impairing function for 6 months' (two of five; at least one from first three):

A. Same as that of schizophreniform disorder. 


\section{B. Impairment of functioning.}

C. Duration for at least 6 months.

Criteria A of schizophreniform disorder or schizophrenia can be remembered by the mnemonic: Delusions Herald Schizophrenic's Bad News. ${ }^{19}$

Other mnemonics for schizophrenia that may be useful are Haldol-D, ${ }^{25}$ A HARD CRASH ${ }^{26}$ and HALDOL BENDER. ${ }^{24}$

\section{Catatonia}

Catatonia associated with another mental disorder (catatonia specifier):

'G-MAN SWEEPS MineCraft' ( $\geq 3$ of 12)

Grimacing, Mannerism, Agitation, Negativism, Stupor, Waxy flexibility, Echolalia, Echopraxia, Posturing, Stereotypy, Mutism, Catalepsy

Other mnemonics that may be helpful are Wired \& Mired ${ }^{27}$ LIMP MEN ${ }^{26}$ and A SLIME-posture. ${ }^{28}$

\section{Bipolar and related disorders}

\section{Manic episode}

An abnormal and persistent elevated, expansive or irritable mood and increased goal-directed activity or energy plus DIGFAST (three or four of seven) for 7 days. Dr William Falk at Massachusetts General Hospital developed the mnemonic DIGFAST. ${ }^{29-31}$ The term may refer to the speed with which a patient who is manic would dig a hole if put to the task, as they may appear as if 'driven by a motor'. ${ }^{19}$

Distractibility

Indiscretion, pleasurable activities with painful consequences

Grandiosity

Flight of ideas/subjective racing thoughts

Activity increased or psychomotor agitation

Sleep need decreased

Talkativeness

Other mnemonics for the manic episode are:

DAFTSIG,${ }^{32}{ }^{33}$ FASTPED,${ }^{34}$ GIDDY HIGH,${ }^{26}$ GRANDIOSE,$^{25}$ IE RATE DIS (emphasises bipolar disorder an IE (ie-that is) RATE DIS (order) or a disorder with variable rates of activity and thinking), ${ }^{35}$ GIDDINESS, ${ }^{36}$ DeTeR the HIGH (Dr Carey Gross developed it), ${ }^{37}$ GREAT SAD, ${ }^{38}$ DR MANIA, ${ }^{23}$ GST PAID, ${ }^{39}$ Grand Sex Through Impulse Distracts (from) Appropriate Pleasure. ${ }^{40}$

\section{Hypomanic episode}

FLIGHTY (The dictionary defines 'flighty' as frivolous, irresponsible, capricious, mercurial and volatile, words that also could describe hypomanic individuals), ${ }^{41}$ TAD HIGH ${ }^{37}$ HIGH- $4 .{ }^{42}$

\section{Major depressive episode/major depressive disorder}

SIG: EM CAPS (five out of nine symptoms for over 2 weeks to fulfil the definition of major depression, including either depressed mood or loss of interest). ${ }^{43}$ That is, an individual must have a depressed mood for at least 2 weeks continuously along with four of eight depressive neurovegetative symptoms. Or an individual may have anhedonia for at least 2 weeks continuously, along with four of the other seven depressive neurovegetative symptoms (without having depressed mood as such). ${ }^{30}$ The eight neurovegetative symptoms of depression can be remembered with the mnemonic 'SIGECAPS' developed by Dr Carey Gross at Massachusetts General Hospital. The mnemonic refers to a prescription one might write for a patient who is depressed and anergic-SIG: Energy CAPSules ('sig' is written before the directions on a prescription)..$^{34} 44$

Suicidal thoughts

Interests decreased

Guilt

Energy decreased

Concentration decreased

Appetite disturbance (increased or decreased)

Psychomotor changes (agitation or retardation)

Sleep disturbance (increased or decreased)

Other mnemonics are C GASP DIE-it overcomes the problem of the two S's (and trying to recall what they stand for) in the mnemonic SIGECAPS. Here, D represents thoughts or acts of death, ${ }^{4546}$ DEPRESSION,,${ }^{25} 47$ DISGUSTED,${ }^{23}$ DEPRESSING,${ }^{48}$ SAMPLEIDS, ${ }^{26}$ Depression Is Worth Seriously Memorizing Extremely Weighty Criteria Sorry, ${ }^{32}{ }^{33}$ Depression Is Worth Studiously Memorizing Extremely Grueling Criteria. Sorry (DIWSMEGCS) ${ }^{49}$ DIGSPACES,${ }^{50}$ DEAD SWAMP ${ }^{51}$ SAD IMAGES, MASS FEE GAP FITS,${ }^{24}$ Two weeks of A SAD FACE,${ }^{52}$ SAD FACES,${ }^{53}$ IN SAD CAGES, ${ }^{54}$ ESCAPISMS (as many patients want to escape their condition),${ }^{55}$ ESCAPERS. ${ }^{56}$

\section{Specifiers for bipolar and related disorders}

With anxious distress: 'CARLoT' (two of five)

Concentration difficulty

Awful or apprehension

Restless

Lose control

Tense or keyed up

With mixed features: manic or hypomanic episode with mixed features: SIG E DR (three of six)

Suicidal thoughts

Interests decreased

Guilt

Energy decreased

Depressed

Retarded

Depressive episode, with mixed features: MIGFAST (three of seven): the acronym is the same as the 'DIGFAST' mnemonic of the manic episode with ' $\mathrm{D}$ ' replaced by ' $\mathrm{M}$ '. M stands for Mood elevated and expansive.

With melancholic features: PRe MED GAP

Pleasure loss; Reactivity loss (one of two)

Three or more of six:

Morning worsening

Early morning awakening

Distinct quality of mood

Guilt

Anorexia 
Psychomotor changes (agitation or retardation)

Other mnemonics that help remember the specifier for melancholic features are: 'MELANcholic': Morning worsening of symptoms/psychoMotor agitation, retardation/early Morning awakening/Mood distinct, Excessive guilt, Loss of emotional reactivity/pLeasure (one of two), Anorexia (or weight loss)/aNhedonia (bestmedicalmnemonics.blogspot.com, 2011), ${ }^{57}$ PAGER MAD, ${ }^{24}$ MAD GRADS. ${ }^{20}$

With atypical features: 'RAILS'20

\section{Depressive disorders}

\section{Disruptive mood dysregulation disorder}

'SITs 3 times per week, irritate others for 1 year, started before 10 years; Not diagnosed first before 6 or after 18 years, neither BIO nor MDD, exclude mania \& others.'

Severe

Inconsistent Temper outbursts

3 or more times per week

Irritable mood in between observed by others

Others (parents, teachers, peers; in at least two of three settings, severe in one)

for 1 year (never without above symptoms for 3 or more consecutive months)

started before 10 years by history or observation

Not diagnosed first before 6 years or after 18 years

Neither coexist with Bipolar, Intermittent explosive, Oppositional defiant disorder nor occur exclusively during MDD

Exclude full symptom criteria of hypomania or mania lasting more than 1 day, or any other mental disorders (substance or medical condition induced also)

\section{Persistent depressive disorder (dysthymia)}

HE'S 2 SAD, ${ }^{58}$ Depressed mood plus CHASE E, ${ }^{59}$ or ACHEWS, ${ }^{21}$ 'the rule of twos: 2 years of depressed mood, 2 of 6 neurovegetative symptoms, no more than 2 months without symptoms. ${ }^{60}$ Six neurovegetative symptoms can be remembered by mnemonic 'SIGECA' (the same mnemonic for depression, except that the last two criteria (psychomotor agitation/retardation and suicidality) and interest decreased, guilt criteria replaced by low selfesteem and hopelessness, respectively), ${ }^{61}$ DESPOND, ${ }^{23}$ HE TAILS, ${ }^{24}$ CHASES. ${ }^{32} 33$

\section{Premenstrual dysphoric disorder}

'SAIL Over CASPIAn SEA 5 Times In 2 months' (five, with one from SAIL, one from Over CASPIAn)

Sad

Anxiety

Irritability

Lability

Overwhelmed or out of control

Concentration

Appetite changes

Sleep changes

Physical symptoms
Interest decreased

Anergia (energy loss)

Symptoms not an Exacerbation of another disorder or Attributable to effects of substance or another medical condition

5-at least five symptoms present

Times-final week before the onset of menses, improve within few days of onset, minimal in the week after menses

In-interference with work or causing distress

2 months-confirmed during at least two symptomatic menstrual cycles

Another mnemonic for premenstrual dysphoric disorder is TOUGH MENSES. ${ }^{23}$

\section{Anxiety disorders}

\section{Separation anxiety disorder}

'HUG PANDaS' (three of eight for 4 weeks in children and adolescents or 6 months in adults) (A child will HUG PANDaS when he or she fears or anticipates separation of major attachment figure).

Harm or loss of an attachment figure

Untoward event that causes separation from attachment figure worry

Going out of home

Physical symptoms with anticipated separation

Alone is a big fear

Nightmares involving the theme of separation

Distress of separation

Sleeping without an attachment figure

Another mnemonic is 'PUSH or NAGS'. ${ }^{19}$

\section{Specific phobia: 'PHOBIA'}

Persistent ( $>6$ months)

Handicapping (restricted lifestyle)

Out of proportion

Beginning immediately and almost always

Intense fear or anxiety about a specific object or situation leading to

Avoidance

Other mnemonics are PHOBIA ${ }^{62}$ and FEARED. ${ }^{24}$

\section{Social anxiety disorder (social phobia)}

\section{FEARED}

Fear of social situations where exposed to possible scrutiny by others; Fears of being negatively evaluated

Exposure to the social situation almost always provokes fear or anxiety

Avoids the social situation or endured with intense fear or anxiety

Recognises that the fear is out of proportion

Exclusion of fear induced by a substance or another mental or medical disorder; Excessive/unrelated to fear of another coexisting medical condition

Distress or impairment; Duration lasting for 6 months

2. ANTI-FEAR

Almost always provoke anxiety or fear of a social situation 
Negative evaluation of patient's act or anxiety symptoms feared

Timing: duration lasting 6 months or more

Impairment or distress in social, occupational or other important areas of functioning

Fear or anxiety about social situations where possible scrutiny by others

Excessive/unrelated to fear of another coexisting medical condition; Exclusion of fear induced by a substance or another mental or medical disorder

Avoidance of social situations or endured with intense fear or anxiety

Recognises out of proportion

Other mnemonics are FAINT ${ }^{63}$ and FEARS. ${ }^{23}$

\section{Panic disorder}

1. A panic attack is an abrupt surge of intense fear or intense discomfort that reaches a peak within minutes and during which four or more of the following symptoms, remembered by the mnemonic 'STUDENTS FEAR 3 C's'. ${ }^{64}$

Sweating

Trembling or shaking

Unsteadiness, dizziness, light headed or faint

Depersonalisation or derealisation

Excessive heart rate, palpitations

Nausea or abdominal distress

Tingling (numbness or paraesthesias)

Shortness of breath or smothering

Fear of dying, losing control or going crazy

3 C's: chest pain, chills, choking

The other criteria can be remembered by using mnemonic 'ABCD'.

2. At least one attack followed by $\geq 1$ month of one or both of:

- Behaviour to avoid having panic attacks, such as avoidance of unfamiliar situations or exercise.

- Concern or worry about the additional panic attack or their consequences.

3. Disturbance not attributable to effects of a substance or another medical or mental disorder.

Another mnemonic for the panic attack: ABC2D2F3P2S2. ${ }^{32}$

The other mnemonics that help remember panic disorder are CATASTROOF ${ }_{3}$ IES, ${ }^{38}$ SUDDENLY SCARY, ${ }^{23}$ STUDENTS,${ }^{65}$ by visualising a patient with panic disorder clutching his chest (heart cluster), hyperventilating (breathlessness cluster), and shaking with fear (fear cluster) and screaming out '355! 355!', ${ }^{21}$ PANICS. ${ }^{66}$

Panic attack specifier: same as criterion 1 of panic disorder.

\section{Agoraphobia}

A. Marked fear or anxiety about two or more of the five situations that can be remembered by the mnemonic 'COOPE' ${ }^{67}$

Crowded area

Open spaces

Outside the home
Public transport

Enclosed spaces

B. Other criteria remembered by mnemonic 'PHOBIA'

Persistent ( $>6$ months)

Handicapping (restricted lifestyle)

Out-of-proportion fear or anxiety

Because of thoughts that escape or help might not be available in the event of developing panic-like symptoms or other incapacitating or embarrassing symptoms

Intense fear or anxiety provoked almost always with the agoraphobic situations

Avoidance

\section{Generalised anxiety disorder}

The criteria of generalised anxiety disorder (GAD) can be remembered by the mnemonic 'WATCHER' (modified by the author from the original mnemonic 'WATCHERS') ${ }^{68}$

Worry and Anxiety

Time for at least 6 months

Controlling the worry difficult

Handicapping

Exclude another mental disorder

Rule out worry, not due to physiological effects of a substance or another medical condition

The symptoms associated with worry and anxiety (three or more of six) can be remembered by the mnemonics: FIRST C, ${ }^{32}{ }^{33}$ MERCI-S, ${ }^{59}$ Macbeth Frets Constantly Regarding Illicit Sins (based on the idea that Macbeth had GAD before and after killing King Duncan), ${ }^{21}$ TICKES, ${ }^{69}$ BE SKIM, ${ }^{65}$ 'Does Mr Fisc worry excessively about minor matters?, MR FISC, ${ }^{70}$ I C REST ('I see rest'). ${ }^{71}$

Other mnemonics for GAD that are useful are STOMACH ${ }^{38}{ }^{72}$ Worry WARTS, ${ }^{73}$ WATCHERS, ${ }^{68}$ AND I C REST,${ }^{71}$ I'M TENSED,${ }^{23}$ DEFICITS,${ }^{26}$ I'M A FICKLE CASE. $^{24}$

\section{Obsessive-compulsive and related disord}

Obsessive-compulsive disorder (OCD): 'Thoughts RIDE TIME, Acts Reduce TIME'

A. Presence of obsessions, compulsions, or both Obsessions: 'Thoughts RIDE'

1. Thoughts, urges or images that are:

Recurrent and persistent.

Intrusive and unwanted.

Distress (anxiety) provoking

2. Effaced by ignoring or suppressing or neutralising with other thought or compulsion.

Compulsions: 'Acts Reduce'

1. Acts, mental or behavioral, repetitively performed in response to an obsession oraccordingto rigid rules.

2. Reduce or prevent anxiety or distress, prevent a dreaded event.

B. Time-consuming or IMpair socio-occupational functioning.

C. Exclude being induced by a substance or another medical condition.

D. Exclude another mental disorder. 
Another mnemonic for OCD: 'REORIENT PATIENT'.

Obsessions:

Recurrent and persistent thoughts, urges, images

Experienced as intrusive and unwanted

Often cause marked anxiety or distress

Resist by ignoring or suppressing the thoughts or neutralise with some other thought or compulsion

Impairing social, occupational and other areas of functioning

Exclude due to substance or another medical condition

Not related to other mental disorder

Time consuming

Compulsions:

Performing in response to an obsession or according to rigid rules

Acts, behavioural or mental, performed repetitively

To prevent or reduce anxiety or distress or

Impair social, occupational and other areas of functioning

Exclude due to substance or another medical condition

Not related to other mental disorder

Time consuming

Other mnemonics that may help remember criteria for OCD:

1. RITUALS (obsessions require first four-RITU, compulsions next two-AL, both require last one-S), REPEATER MRS PETER (obsessions require REPEATER; compulsions require MRS; both require PETER),${ }^{23} \mathrm{~A}$ BIT FORCED,${ }^{24}$ RESIDENT PRISONER, ${ }^{72}$ RITUAL. ${ }^{25}$

\section{Body dysmorphic disorder: 'PAIN'}

Preoccupation with perceived defects or flaws in physical appearance

Acts, mental or behavioural, repetitive, in response to appearance concerns

Impairment in socio-occupational functioning

Not due to an eating disorder

Hoarding disorder: 'PILED'

Perceived need to save items and distress associated with discarding them results in

Inability to discard or parting possessions regardless of their actual value

Litter up possessions

Exclude another medical condition or another mental disorder

Distress or dysfunction in socio-occupational functioning

\section{Trichotillomania (hair-pulling disorder): 'HAIR'}

Hair loss, due to recurrent pulling out of one's hair

Attempts repeatedly to decrease or stop hair pulling

Impairment in socio-occupational functioning or cause significant distress

Rule out another mental or medical disorder that causes hair loss

\section{Excoriation (skin-picking) disorder: 'SKIN'}

Skin picking resulting in skin lesions
Keen to decrease or stop skin picking by repeated attempts

Impairment in socio-occupational functioning or cause significant distress

Not attributable to substance-induced, another medical or mental disorder.

Trauma and stressor-related disorder Reactive attachment disorder: 'LACK In EMPATHY'

Limited or Absent or Changing

(K) Caregivers for forming stable and selective attachments

Induce

Emotionally withdrawn or inhibited behaviour by not seeking or responding to comfort when distressed and

Minimal social and emotional responsiveness

Positive affect limited

Appearance of episodes of unexplained irritability or sadness or fearfulness even evident during nonthreatening situations

To exclude ASD

Has a developmental age of at least 9 months before 5 Years

Disinhibited social engagement disorder: LACK In WARING

Limited or Absent or Changing

(K) Caregivers for forming stable and selective attachments

Induce

Willingness to go off with unfamiliar adults

Absent or diminished checking back with an adult caregiver after venturing away, even in unfamiliar situations

Reduced or absent reticence in approaching or interacting with unfamiliar adults

Inappropriate overly familiar verbal or physical behaviour

Not limited to impulsivity (as in ADHD)

Got developmental age of at least 9 months

Post-traumatic stress disorder (PTSD): 'TRAAUMA' (modified by the author from the original mnemonic TRAUMA) $)^{37} 7475$

Traumatic event: witnessed or experienced or occurred to dearest or exposure repeatedly to its aversive details

Re-experience one of following intrusion symptoms: memories, nightmares, flashbacks, psychological distress or physiological reaction to cues symbolising the traumatic event

Avoidance of memories, thoughts, feelings of the traumatic event or its reminders

Alterations in cognitions and mood negatively: forgetting, mislabelling, blaming, no positive emotions, always negative emotions, anhedonia, detachment (two of seven)

Unable to function or cause distress/Unattributed to a substance or another medical condition

Month or more of symptoms

Arousal and reactivity increased with two of the following: irritability, recklessness, hypervigilance, startling, concentration and sleep disturbances 
The subcriteria to symptom clusters of PTSD can be remembered by ${ }^{75}$ :

(1) Intrusion symptoms: 'R3D2' (think Star Wars and add an ' $R$ ') which stands for

Recollections, Recurring and Reactivity (physiological) in response to cues of the traumatic event; Dreams (distressing) and Distress (psychological).

(2) Avoidance, negative cognitions/mood and dissociative symptoms: 'AFRAID' (modified by author)

Avoid internal or external stimuli associated with the trauma

False cognitions (mislabelling and blaming)

Recall difficulty

Affect (no positive, always negative emotions)

Interest (diminished)

Detachment

(3) Arousal symptoms: 'SCARE' (modified by the author)

Sleep disturbance

Concentration (difficulty)

Anger (outbursts or irritability)

Really vigilant/Reckless or self-destructive behaviour

Exaggerated startle response

Other mnemonics for PTSD that may help are: FIGHT, ${ }^{76}$ DREAMS ${ }^{38}$ CRASH,${ }^{23}$ PRIDE AFRAID CHAINS, ${ }^{24}$ ERAA. ${ }^{32}$

Acute stress disorder: the subcriteria to symptom clusters of acute stress disorder can be remembered by: 'R3D2 AFRAID SCARE' (similar to PTSD) (presence of nine or more of the following 14 symptoms):

Intrusion symptoms:

Recollect (memories) (1), Dreams (distressing) (2), Recurring (flashbacks) (3), Reactivity (physiological) and Distress (psychological) in response to cues of the traumatic event (combined as 4).

Negative mood, dissociative and avoidance symptoms (cognitive symptoms removed):

Avoid internal (5) or external (6) stimuli associated with the trauma

(False cognitions (mislabelling and blaming) removed)

Recall difficulty (7)

Affect (no positive emotions) (8)

('Interest diminished' removed)

Detachment (9).

Arousal symptoms:

Sleep disturbance (10)

Concentration (difficulty) (11)

Anger (outbursts or irritability) (12)

Really vigilant (13)

Exaggerated startle response (14)

Adjustment disorder: 'EMOTES' (modified by the author $^{23}$

Emotional or behavioural symptoms within 3 months of onset of stressor(s) with

Marked distress in excess of what would be expected from exposure to the stressor (or)

Occupational, academic or social functioning is significantly impaired
Termination of symptoms within 6 months oftermination of stressor or its consequences

Exclusion of another mental disorder or exacerbation of pre-existing mental disorder ruled out

Symptoms do not represent bereavement

Another mnemonic for adjustment disorder: IT'S BAD. ${ }^{24}$

\section{Dissociative disorders}

Dissociative identity disorder: 'DID'

Disruption of identity with two or more distinct personality states including

Inability to recall properly traumatic events and/or everyday events or personal information

Distress or impairment in socio-occupational functioning

Depersonalisation/derealisation disorder: 'DREAM' (modified by the author) ${ }^{25}$

Detachment experiences

Reality testing intact

Exclude other primary mental disorders

Attributable not to a substance or another medical condition

Marked distress caused by symptoms

\section{Somatic symptom and related disorders}

Somatic symptom disorder: the B criterion can be remembered by the mnemonic 'TEA'.

Thoughts: disproportionate and persistent about the seriousness of somatic symptoms

Emotion: persistently high anxiety about health or symptoms

Actions: excess time and energy devoted to these symptoms

Illness anxiety disorder. 'Persistent search for any big disease'

Preoccupation of having or acquiring an illness

Somatic symptoms absent or of mild intensity/Significant preoccupation about the risk of developing or for an existing disease

For at least 6 months

Anxiety about health

Behaviour-excessive health-related behaviours (careseeking type) or maladaptive avoidance (care-avoidant type)

Disturbance not better explained by another mental disorder

Conversion disorder (functional neurological symptom disorder): 'CONVERSION' ${ }^{, 77}$

Feeding and eating disorders

Anorexia nervosa: 'Weight Fear Bothers Anorexics' (modified by the author ${ }^{19}$

Significantly low body Weight in the context of age, sex, developmental trajectory and physical health

Fear of gaining weight or becoming fat or persistent behaviour that interferes with weight gain

Body weight and shape are perceived in a distorted way 
Seen in Anorexics

Other mnemonics for anorexia nervosa: RAID, ${ }^{32} 33$ FLAB,${ }^{25}$ I FEAR LARD. ${ }^{24}$

Bulimia nervosa: 'Bulimics Over-Consume Pastries'19 21

Recurrent episodes of Binge eating (at least once a week for 3 months) with a sense of

Out of control overeating

Excessive Concern with body shape and weight

Purging behaviours, such as self-induced vomiting, misuse of laxatives, diuretics, enemas, or other medications; fasting; excessive exercise

Other mnemonics that may help remember criteria for bulimia nervosa: A BINGE, ${ }^{24}$ BASTE,${ }^{78}$ BORCEN, ${ }^{72}$ BINS, ${ }^{32} 33$ FRIDGES. ${ }^{25}$

\section{Sleep-wake disorders}

Insomnia disorder: 'SLEEP' (modified by the author) ${ }^{23}$

Sleep quantity or quality dissatisfaction associated with one or more of difficulty initiating, maintaining, returning back to sleep

Lasting for at least 3 months, occurring at least three times a week despite adequate opportunity for sleep, causing significant distress or impairment

Exclude this diagnosis if a disturbance occurs exclusively during the course of another sleep-wake disorder

Exclude the complaint of insomnia not being due to coexisting mental and medical disorders

Physiological effects of a substance do not attribute to insomnia

Hypersomnolence disorder: 'SLEEP LOT' (modified by the ${\text { author })^{23}}^{23}$

Sleep excess despite the main sleep period lasting at least 7 hours

Lasting for at least 3 months, occurring at least three times a week, causing significant distress or impairment

Excludes this disorder if disturbance occurs exclusively during the course of another sleep disorder

Exclude the excess sleep not being due to coexisting mental and medical disorders

Physiological effects of a substance do not directly attribute to hypersomnolence

The three subcriteria of criterion A can be remembered by:

Lapses into sleep recurrently within the same day or

Overcoming sleepiness and being awake is difficult after abrupt awakening or

Time spent on the main sleep episode is more than 9 hours though unrefreshing.

Narcolepsy: 'CHES'

Cataplexy or

Hypocretin deficiency or

Evidence in sleep studies (polysomnography or multiple sleep latency test) in the presence of

Sleep attacks (recurrent daytime naps or lapses into sleep)

Mnemonics that may help in remembering the criteria and associated symptoms of narcolepsy: CHESS $^{79}$ and CRASH $^{80}$
Breathing-related sleep disorders

Obstructive sleep apnoea-hypopnoea

A mnemonic validated for screening obstructive sleep apnoea-hypopnoea is STOP-BANG. It is a simple, easyto-remember and self-reportable screening tool, which includes four subjective (STOP: Snoring, Tiredness, Observed apnoea and high blood Pressure) and four demographic items (BANG: BMI, Age, Neck circumference, Gender) ${ }^{81}$ The DSM V criteria and associated features can be remembered by this mnemonic.

\section{Parasomnias}

\section{Non-rapid eye movement sleep arousal disorders}

'Forgets or recalls little of incomplete awakening happened while walking or shouting during the first third of sleep'.

Forgets (amnesia of) the episodes

Recalls little of dream imagery during episodes of

Incomplete awakening from sleep presenting as

Sleepwalking or

Shouting (sleep terrors)

During the first third of sleep

Restless legs syndrome: 'URGE' 82

Urge to move

Rest induced

Gets better with activity and

Evening and night accentuation

Disruptive, impulse control and conduct disorders

Oppositional defiant disorder

When children and adolescents are oppositional and defiant, they act like 'REAL BADS' ${ }^{\text {'19 }}$ (four of eight symptoms within the last 6 months).

Resentful

Easily annoyed

Argues with adults

Loses temper

Blames others for his or her misbehaviour

Annoys people deliberately

Defies rules or requests

Spiteful

\section{Conduct disorder}

The behaviours of conduct disorder are 'BAD FOR A BUSINESS $^{19}$ (three of the following 15 criteria in the past 12 months, with at least one present in the past 6 months)

Bullying

Animal cruelty

Destroying others' property

Fighting

Out late at night

Running away from home

Actively forcing sex

Being cruel to people

Using a weapon

Setting fires

Into someone's house, building or car

Not going to school 
Everyday lying or conning others

Stealing while confronting a victim

Stealing without confronting a victim

The four categories of criteria for conduct disorder can be remembered by the mnemonic 'TRAP'. 83

Theft-breaking and entering, deceiving, nonconfrontational stealing

Rule breaking — running away, skipping school, out late Aggression-people, animals, weapons, forced sex

Property destruction

Another mnemonic that may be helpful is DDAVP. ${ }^{24}$

\section{Substance-related and addictive disorders}

\section{Substance use disorders}

'Haphazard knowledge of or failure to control problems in activities urges excess tolerance with time'

Hazardous use

Use despite knowledge of having a persistent or recurrent physical or psychological problem caused or exacerbated by the substance

Failure to fulfil major role obligations at work, school or home

Persistent desire to cut down or control substance use and report multiple unsuccessful efforts to decrease or discontinue use

Use despite social or interpersonal problems caused or exacerbated by the substance

Important social, occupational or recreational activities given up or reduced

Intense urge or desire for the drug (craving)

Taking in excess amounts or over a longer period than was originally intended

Tolerance

Withdrawal

A great deal of time is spent for obtaining or using the substance or recovering from its effects

Another mnemonic is: 'WITHDRAW THE substance'.

Work, school or home obligation failures

Interpersonal or social consequences

Time spent too much for obtaining, using or recovering from effects of substance

Hazardous use

Desire for the drug

Reinstatement

Activities (important or recreational) given up

Withdrawal

Tolerance

Harmful use

Exceed the intended amount or time

Other mnemonics available for remembering DSM V criteria are:

1. The Wise Know: Decline Tender Loving Care And Respect Silver Hair. ${ }^{84}$

2. 'CHEW THAT COP'. 85

Other mnemonics that may aid in remembering the criteria of substance dependence in the Text Revision of Fourth Edition of DSM (DSM IV-TR) are ADDICTD, ${ }^{86}$ WHATCAT, ${ }^{87}$ WE are unable TO CUT our drinking, ${ }^{88}$
Tempted With Cognac, ${ }^{21}$ ROLAID PUPILS, ${ }^{24}$ PEWTERR, ${ }^{89}$ TWO 6 PACK, ${ }^{90}$ Won't Resist Imbibing and Seeks Tipple Every Night, ${ }^{91}$ I DRANK MORE. ${ }^{23}$ The behavioural patterns of compulsive substance use that is characteristic of dependence in DSM IV-TR can be remembered by the mnemonic 'TEACH'. ${ }^{92}$ The criteria for substance abuse in DSM IV-TR can be remembered by the mnemonics: CLOD,${ }^{92}$ WILD, ${ }^{89}$ FOLD,${ }^{87}$ "When alcohol takes HOLD of you', ${ }^{88}$ DRiNK, ${ }^{90}$ FAILS. $^{23}$ The DSM V criteria for substance use disorder are a combination of DSM IV-TR dependence and abuse criteria, with the 'craving' criterion added and 'legal consequences' criterion removed. ${ }^{93}$ The mnemonics 'WILD PEWTERR' ${ }^{89}$ and 'DRiNK TWO 6 PACK $^{, 90}$ represent this combination.

\section{Alcohol intoxication}

The six features from criterion $\mathrm{C}$ can be remembered by the mnemonic: SAM'S GIN. ${ }^{94}$

\section{Alcohol withdrawal}

The eight features of criterion B can be recalled using the mnemonic: PAST NITE. ${ }^{94}$

\section{Cannabis intoxication}

The four features in criterion $\mathrm{C}$ can be recalled by the mnemonic: MEAT. $^{94}$

\section{Phencyclidine intoxication}

At least two of eight features from criterion C develop within an hour of phencyclidine use. These eight features can be recalled by the mnemonic: MAP STAND. ${ }^{94}$

\section{Other hallucinogen intoxication}

Criterion D can be recalled using the mnemonic: DISTORT. $^{94}$

\section{Inhalant intoxication}

The 13 criterion $\mathrm{C}$ features can be recalled using the mnemonic: DISRUPTS GLOBE. ${ }^{94}$

\section{Opioid intoxication}

Pupillary constriction (or dilation following an overdose) is present along with one of three features from criterion C. These three features of criterion $\mathrm{C}$ can be recalled by the mnemonic SAD. ${ }^{94}$

\section{Opioid withdrawal}

These nine features from criterion B can be recalled by the mnemonic: ARMY FINDS (as in a possible headline: Army finds Opioid Withdrawal In Troops). ${ }^{94}$

\section{Sedative, hypnotic or anxiolytic intoxication}

The six features from criterion $\mathrm{C}$ can be remembered by mnemonic: SAM'S GIN. ${ }^{94}$

\section{Sedative, hypnotic or anxiolytic withdrawal}

The eight features of criterion B can be recalled using the mnemonic: PAST NITE (as in an individual who is experiencing symptoms of withdrawal from decreased intake over the past several nights). ${ }^{94}$ 


\section{Stimulant intoxication}

The nine features from criterion $\mathrm{C}$ can be recalled using the mnemonic: A CODE BLUE. ${ }^{94}$

\section{Stimulant withdrawal}

The five features from criterion $\mathrm{B}$ can be recalled by the mnemonic 'PANTS' (as in an individual who pants when out of breath). ${ }^{94}$

\section{Neurocognitive disorders}

Delirium: ' $4 A$ and $3 C$ '

Disturbance in Attention and

Awareness

Abrupt or Acute onset with

Altering in severity during the course of a day

Cognitive disturbance

Consequence of another medical condition or substance related

Can't explained by another neuroCognitive disorder or Coma

Another mnemonic that may help in remembering the diagnostic criteria is 'Medical FRAT'.21

Mnemonics that may aid in remembering the criteria and supporting features of delirium are:

DELIRIUM, ${ }^{95}$ PHYSICAL, ${ }^{96}$ 'C, DIPPS', 97 FEELS SPACED, ${ }^{38} 72$ CCCC. $^{32} 33$

\section{Major and mild neurocognitive disorder}

The neurocognitive domains can be remembered using the mnemonic SAMPLE.

Social cognition

Attention

Memory and learning

Perceptual motor

Language

Executive function

\section{Major neurocognitive disorder: 'DIRE'}

Decline from a previous level of performance in one or more cognitive domains

Interfere with independence in everyday activities

Rule out delirium

Exclude another mental disorder

Another mnemonic that may be helpful: DEMENTIA. ${ }^{95}$

\section{Personality disorders}

\section{General personality disorder: 'AIM COIN As Per Distance'}

An enduring pattern of inner experience and behaviour that deviates markedly from the expectations of the individual's culture. Manifested in two (or more) of the following areas:

Affectivity

Impulse control

Cognition

Interpersonal functioning

Adolescence or early adulthood onset

Pervasive and inflexible across a broad range of personal and social situations
Distress or impairment in social, occupational or other important areas of functioning

Cluster A personality disorders

Paranoid personality disorder: SUSPECT, ${ }^{3798}$ GET FACT. $^{24} 69$ Schizoid personality disorder. DISTANT, ${ }^{37} 98$ SIR SAFE, ${ }^{24}$ DISORDER, ${ }^{23}$ CLOSED IN. ${ }^{25}$

Schizotypal personality disorder: ME PECU-

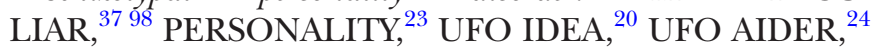
PERCEPTS. ${ }^{25}$

Cluster B personality disorders

Antisocial personality disorder: CORRUPT, ${ }^{3798}$ CALL ASPD, ${ }^{14}$ CALLOUS MAN, ${ }^{24}$ CAR FIRM WAGER. ${ }^{72}$

Borderline personality disorder: AM SUICIDE, ${ }^{98}$ DESPAIRER, ${ }^{37}$ DISTURBED,${ }^{23}$ BIAS IRA, ${ }^{72}$ I RAISED A PAIN $^{24}$ I DESPAIR ${ }^{99}$ I DESPAIRR, ${ }^{44}$ PRAISE, ${ }^{100}$ IMPULSIVE, ${ }^{101}$ ARISES MAD, ${ }^{32}{ }^{33}$ LABILITY $^{25}$ I'M A SAP (criticised as being stigmatic), ${ }^{102} 103$ DARE. ${ }^{104}$

Histrionic personality disorder. PRAISE ME, ${ }^{37} 98$ ACTRESSS,${ }^{29}$ I CRAVE SIN,${ }^{24}$ SEDUCTIVE, ${ }^{23}$ Five S's. ${ }^{25}$

Narcissistic personality disorder: $\mathrm{SPE}_{3} \mathrm{CIAL},{ }^{98}$ GRANDIOSE, ${ }^{37105}$ SELF-IMPORT, ${ }^{23}$ A FAME GAME, ${ }^{24}$ Five E's. ${ }^{25}$

Cluster C personality disorders

Avoidant personality disorder: CRINGES, ${ }^{37} 98$ RESERVED, ${ }^{23}$ RIDICULE. ${ }^{24}$

Dependent personality disorder. RELIANCE, ${ }^{37} 98$ DEPENDENT, ${ }^{23}$ DARN HUT, ${ }^{24}$ FEARS. $^{20}$

Obsessive-compulsive personality disorder: LAW FIRMS, SCRIMPER, ${ }^{37}$ COMPULSIVE, ${ }^{23}$ PERFECTION,${ }^{20}$ LOW MIRTH. ${ }^{24}$

The mnemonics of individual personality disorders are only enumerated without description, as most of them are described together in the provided references.

\section{Medication-induced movement disorders and other adverse effects of medication}

Neuroleptic-induced parkinsonism; other medication-induced parkinsonism: the mnemonic 'TRAP (tremor at rest, rigidity, akinesia and bradykinesia, and postural instability)' used for describing cardinal features of parkinsonism can also be used for remembering the criteria of this disorder. ${ }^{106}$

Neuroleptic malignant syndrome (NMS): the mnemonic FEVER (Fever, Encephalopathy, Vital sign unstable, Enzyme elevation, Rigidity) can help identify clinical and laboratory NMS markers in patients. ${ }^{107}$ Another mnemonic that aids in remembering the criteria of NMS is: RECTAL. ${ }^{108}$

Antidepressant discontinuation syndrome: FINISH. ${ }^{109}$

\section{DISCUSSION}

The objective of this review is to scope the field and to summarise the mnemonics as presented across articles rather than to synthesise or distil the articles to make a qualitative meta-synthesis. Any memoryimproving strategy can be termed a mnemonic strategy. 
It becomes the most useful memory aid when one needs to remember items in a sequence or where there are no meaningful connections to be made between the items. ${ }^{110}$

\section{Main findings}

Mnemonics usage in psychiatry started as it moved towards the medical model with more emphasis placed on making diagnostic criteria. The use of diagnostic criteria started with DSM III and its revision classifications, as the diagnosis of mental disorders moved towards an atheoretical, descriptive approach. This approach led to the practical problem of recalling a large number of complex criteria by clinicians, especially by the primary care physicians. To overcome this problem and in search of tools that assist in recalling these criteria, clinicians started developing and publishing mnemonics in journals and chapters in the textbooks. The use of mnemonics helps in screening or recognising various disorders and may avoid misdiagnosis or delay in accurate diagnosis. ${ }^{34} 3842$ They were also reported as being developed or modified by some authors, largely as an outcome of several years of experience in teaching psychiatry and medical students. Most of the mnemonics are related in some way to the disorder itself, facilitating easy recall. The students may use them for their training and completion of certification examinations. ${ }^{32} 110111$ Some mnemonics were developed or modified to overcome the limitations of certain previous mnemonics that are phonologically, heuristically and aesthetically less than ideal for meaningful assimilation and practical application. ${ }^{45}$ One of the mnemonics published was criticised for being stigmatic. ${ }^{102} 103$ Similarly, disagreement had arisen over the possession of mnemonics and resolved. ${ }^{75}$

\section{Strengths and limitations}

There are many sources of mnemonics for the diagnostic criteria and can be time consuming to go through many phrases from different sources for the same condition. Little work was done until now in the systematic compilation of these mnemonics. This was further restricted to selected topics like DSM IV personality or substance use disorders or description of a single mnemonic for each major psychiatric disorder. ${ }^{25} 263233379498$ The recently published fifth edition of the American Psychiatric Association's DSM V largely continues the previous edition's criterion-based descriptive approach. To date, this is the first review that gathered almost all the available acrostic sentences and acronyms that aid in remembering diagnostic criteria of most of the psychiatric disorders in DSM $\mathrm{V}$. Electronic search for the mnemonics may miss some of the mnemonics that were described in the older books or journals not available online. Some original mnemonics are modified by the author to cater to the changed criteria of some of the disorders in DSM V. These are intended to be used in conjunction with DSM V classification and not a substitute for it.

\section{Future recommendations}

There is a need to validate the usefulness of mnemonics for remembering the criteria of psychiatric disorders. A survey can be conducted on clinicians, academicians and students about their previous or current mnemonic usage in clinical practice or in preparation for exams. A single or group of mnemonics can be provided to them and assess their perceived helpfulness. Reliability and validity indices of the usefulness of a specific mnemonic or preference of a particular mnemonic over others for a specific disorder can be found. Additionally, a study that compares the clinical or learning outcomes between those who were exposed to mnemonics and those who were not can be carried out. Further, the mnemonics that aid in the treatment of psychiatric disorders need to be reviewed and validated as well.

\section{Implications}

Despite several studies showing the effectiveness of mnemonic strategies, these remain the least frequently used formal memory aid in medical practice. The present compilation helps the clinicians or the students memorise a mnemonic for a particular DSM mental disorder that is fascinating for them. They can further create their mnemonics as one's own mnemonics are often the best and, therefore, more memorable. They can also experiment with other types of mnemonics such as picmonics, rhymes and peg words that are not described in the present review.

Funding The authors have not declared a specific grant for this research from any funding agency in the public, commercial or not-for-profit sectors.

Competing interests None declared.

Patient consent for publication Not required.

Provenance and peer review Not commissioned; externally peer reviewed.

Open access This is an open access article distributed in accordance with the Creative Commons Attribution Non Commercial (CC BY-NC 4.0) license, which permits others to distribute, remix, adapt, build upon this work non-commercially, and license their derivative works on different terms, provided the original work is properly cited, appropriate credit is given, any changes made indicated, and the use is non-commercial. See: http://creativecommons.org/licenses/by-nc/4.0/.

ORCID iD

Pavan Kumar Kadiyala http://orcid.org/0000-0001-9268-0549

\section{REFERENCES}

1 Parkin AJ. Improving memory. In: Memory and amnesia an introduction. 2nd edn. Oxford, UK: Blackwell publishers, 1997: 57-9.

2 Worthen JB, Hunt RR. Mnemonic Techniques: Underlying Processes and Practical applications. In: Byrne JH, Menzel R, eds. Learning and memory: a comprehensive reference. 2nd edn. Oxford, UK: Elsevier Ltd, 2017: 1. 515-28.

3 Evan RL. Introduction Mnemonics. In: Every good boy deserves Fudge: the book of mnemonic devices. New York, USA: Penguin Group Inc, 2007: 1-5.

4 American Psychiatric Association. Diagnostic and statistical manual of mental disorders. 5th edn. Arlington, VA: American Psychiatric Publishing, 2013.

5 Grant MJ, Booth A. A typology of reviews: an analysis of 14 review types and associated methodologies. Health Info Libr J 2009;26:91-108. 
6 Munn Z, Peters MDJ, Stern C, et al. Systematic review or scoping review? guidance for authors when choosing between a systematic or scoping review approach. BMC Med Res Methodol 2018;18:143.

7 Arksey H, O'Malley L. Scoping studies: towards a methodological framework. Int J Soc Res Methodol 2005;8:19-32.

8 Levac D, Colquhoun H, O'Brien KK. Scoping studies: advancing the methodology. Implementation Sci 2010;5:69.

9 Finfgeld-Connett D, Johnson ED. Literature search strategies for conducting knowledge-building and theory-generating qualitative systematic reviews. J Adv Nurs 2013;69:194-204.

10 Pham MT, Rajić A, Greig JD, et al. A scoping review of scoping reviews: advancing the approach and enhancing the consistency. Res. Syn. Meth. 2014;5:371-85.

11 Harzing AW. Publish or perish, available from, 2007. Available: https://harzing.com/resources/publish-or-perish

12 Mueen Ahmed KK, Al Dhubaib B. Zotero: a bibliographic assistant to researcher. J Pharmacol Pharmacother 2011;2:303-5.

13 Booth A. "Brimful of STARLITE": toward standards for reporting literature searches. J Med Libr Assoc 2006;94:421-9. e205.

14 Benoot C, Hannes K, Bilsen J. The use of purposeful sampling in a qualitative evidence synthesis: a worked example on sexual adjustment to a cancer trajectory. BMC Med Res Methodol 2016;16:21.

15 Pears R, Shields G. What is referencing? In: In: Cite them right the essential Referencing guide. 11th edn. London, UK: Red Globe Press, 2019: 1-3

16 Akunjee M, Jalali S, Siddiqui S. Development Assessment, Paediatrics. In: The easy guide to OSCEs for specialties: a step-bystep guide to OSCE success. Oxford, UK: Radcliffe Publishing Ltd, 2009: 139-40.

17 Haroon M. Psychiatry. In: Mnemonics for paediatrics. Chesire, UK: PasTest Ltd, 2006: 51.

18 Webster CDet al. The Characteristics of Autism. In: Webster CD, Konstantareas MM, Oxman J, et al, eds. Autism: new directions in research and education. New York, USA: Pergamon Press, 1980: 5-10.

19 Stubbe D. Child and adolescent psychiatry: a practical guide. Philadelphia, USA: Lippincott Williams \& Wilkins, 2007.

20 Puri B, Hall A, Ho R. Revision notes in psychiatry. 3rd edn. Florida, USA: CRC press, 2014

21 Carlat DJ. How to Memorize the DSM-IV-TR Criteria. In: In: the psychiatric interview: a practical guide. 2nd edn. Philadelphia, USA: Lippincott Williams \& Wilkins, 2005: 106-16.

22 Sadek J. Appendices C: Sadek ADHD Checklist (SAC). In: Clinician's Guide to ADHD Comorbidities in Children and Adolescents. Case studies. Switzerland: Springer International Publishing 2019:122-3.

23 Rosenberg LI. The authoritative guide to psychiatric diagnosis. 2nd edn. New Jersey, USA: Garz Publications, 2003.

24 Robinson DJ. Mnemonics \& More: For Psychiatry. 3rd edn Michigan, USA: Rapid Psychler Press, 2001.

25 Keshavan MS. Mnemonics for DSM-IV psychiatric disorders: Part II. Asian J Psychiatr 2010;3:41-2.

26 Swartz CM. Seven mnemonics for some common psychiatric applications. The Journal of Nervous \&amp Mental Disease 1998;186:58-9.

27 Carroll BT, Thomas C, Jayanti K. Treating persistent catatonia when benzodiazepines fail. Current Psychiatry 2005;4:56-64.

28 Denysenko L, Sica N, Penders T, et al. Catatonia in medically ill patients: etiology, diagnosis, and treatment. The Academy of consultation-liaison psychiatry evidence-based medicine Subcommittee monograph. Ann Clin Psychiatry 2018;30:140-55.

29 Ghaemi N, Sachs GS, Goodwin FK. What is to be done? controversies in the diagnosis and treatment of manic-depressive illness. World J Biol Psychiatry 2000;1:65-74.

30 Ghaemi SN. Diagnosis and Description of Mood Disorders. In: Mood disorders: a practical guide. Philadelphia, USA: Lippincott Williams \& Wilkins, 2003: 2-15.

31 Schneider RK, Levenson JL. Mood Disorders. In: Psychiatry essentials for primary care. Philadelphia, USA: American College of Physicians, 2008: 90.

32 Reeves RB. Bullen JA: mnemonics for ten DSM-IV disorders. J Nerv Ment Dis 1995;138:550-1.

33 Reeves, RR, Booker JG. Mnemonics suggested for DSM-IV diagnostic criteria. J Am Osteopath Assoc 1997;97:191.

34 Bost RH. 'Bridge' between knowledge and practice in diagnosing depression. J Am Osteopath Assoc 1997:97:49-52.

35 Reite M, Ruddy J, Nagel K. DSM-IV-TR diagnostic criteria for insomnia related to an Axis I or Axis II disorder. In: Concise guide to evaluation and management of sleep disorders. 3rd edn. Michigan, USA: American Psychiatric Pub, 2002: 189-90.
36 Rundell JR, Mania WMG. Mania. In: Concise guide to consultation psychiatry. 2nd edn. Washington DC, USA: American Psychiatric Press, 1994: 67.

37 Caplan JP, Stern TA. Mnemonics in a mnutshell: 32 AIDS to psychiatric diagnosis. Current Psychiatry 2008;7:27-33.

38 Short DD, Workman EA, Morse JH, et al. Mnemonics for eight DSMIII-R disorders. Psychiatric Services 1992;43:642-4.

39 Kumar V. Introduction to psychiatric disorders. In: Getting started in psychiatry: a guide for junior registrars. Sydney, Australia: Sydney West and Greater Southern Psychiatry Training Network, 2019. https://www.wslhd.health.nsw.gov.au/Education-Portal/Medical/ Psychiatry/Psychiatry-Education

40 Maris RW. Mood Stabilizers and Antiepileptics. In: Pillaged: psychiatric medications and suicide risk. South Carolina, USA: University of South Carolina Press, 2015: 75-97.

41 Wagner DL. FLIGHTY patients a clue to hypomania. Current Psychiatry 2007;6:116.

42 Chiu JF, Chokka PR. Mnemonic for the diagnosis of Hypomania associated with bipolar II disorder. Can J Psychiatry 2003;48:771.

43 Azzam A, Kaftarian E. Unipolar depressive disorders. In: First aid for the psychiatry boards. New York, USA: The McGraw-Hill Companies, 2010: 19-30.

44 Carlat DJ. The psychiatric review of symptoms: a screening tool for family physicians. Am Fam Physician 1998;58:1617-24.

45 Abraham PF, SHIRLEY ER. New mnemonic for depressive symptoms. Am J Psychiatry 2006;163:329-b-30.

46 Minerva. BMJ 2006;332:372.

47 Blenkiron P. A mnemonic for depression. BMJ 2006;332:551.3.

48 Criss TW. Depression. In: Kilgus MD, Rea WS, eds. Essential psychopathology casebook. New York, USA: WW Norton and Company, 2014: 185-6.

49 Black DW, Andreasen NC. Mood Disorders. In: Introductory textbook of psychiatry. 6th edn. Washington DC, USA: American Psychiatric Publishing, Inc, 2014: 166.

50 Patricia D, Price DW. Diagnosis and treatment of major depression. Perm J 2007;11:35-42.

51 Theodore DD. Mood Disorders. In: Textbook of mental health nursing. 2nd vol. New Delhi, India: Reed Elsevier India Private Limited, 2015: 184

52 Goldman HH. Psychiatric Diagnosis and Psychosocial Formulation. In: Review of general psychiatry. New York, USA: Lange Medical Books/McGraw-Hill, 1984: 144.

53 Tucker P, Morgan JS. Mood Disorders. In: Psychiatry. Ventura, CA: Biotest Publishing Company, 2002: 93.

54 Rund DA, Hutzler J. In sad cages: a mnemonic for depression. Am $J$ Psychiatry 1983;140:641.

55 Guerra T. Neuro/Psych Mnemonic Flashcards. In: Memorizing pharmacology mnemonics: pharmacology Flashcards and Fill-ins for the future nurse, doctor, physician assistant and pharmacist. North Carolina: Lulu Press, 2018: 270.

56 Rund DA. Symposium Overview Psychiatric emergencies: Challenge and Oppurtunities for Emergency Health Services. In: O'Neill ES, ed. The psychiatric emergency: its recognition and management. New York, USA: The Haworth Press, 1986: 3. 5-9.

57 Mohammed N. Depression: melancholic features (DSM IV), 2011. Available: http://bestmedicalmnemonics.blogspot.com/2011/01/ depression-melancholic-features-dsm-iv.html

58 Christman DS. 'HE'S 2 SAD' detects dysthymic disorder. Current Psychiatry 2008;7:120.

59 Ghaemi SN. The Unipolar Depressive Spectrum. In: Mood Disorders: A Practical Guide. Philadelphia, USA: Lippincott Williams \& Wilkins 2003:16-19.

60 Byatt N, Disorders M. In: Aghababian RV, eds. In: Essentials of emergency medicine. 645. 2nd edn. Massachusetts, USA: Jones \& Bartlett Learning, 2011

61 Carandang CG, Martin A. Clinical Assessment of Children and Adolescents with Depression. In: Rey MJ, Birmaher B, eds. Treating child and adolescent depression. Philadelphia, USA: Lippincott Williams \& Wilkins, 2009: 27-8.

62 Elder R, Evans K, Nizette D. Anxiety disorders. In: Psychiatric \& Mental Health Nursing. 2nd edn. NSW, Australia: Elsevier Publishers, 2009: 38

63 Berber M. Recognizing social anxiety disorder. Can J Psychiatry 2004; $49: 645$.

64 Beck RW. Psychoneurological aspects. In: Functional neurology for practitioners of manual medicine E-Book. 2nd edn. London, UK: Churchill Livingstone Elsevier Ltd, 2011: 306-7.

65 Arnold A, Dash M. Psychiatry. In: Arnold A, Dash M, eds. Guide to the Canadian family medicine examination. New York, USA: Mc Graw Hill Education, 2013: 130. 130. 
66 Le T, Bhushan V. First aid for the USMLE step 1 2015. New York, USA: McGraw Hill Professional, 2014: 512.

67 Knowmedge. Agoraphobia criteria. Available: https://knowmedge. com/medical_mnemonics/Psychiatry_mnemonics/AgoraphobiaCriteria/1597 [Accessed 30 Aug 2019].

68 Berber MJ. WATCHERS: recognizing generalized anxiety disorder. $J$ Clin Psychiatry 2000;61:447.

69 Raj YP. The patient with depressive symptoms. In: Jiang W, Gagliardi JP, Krishnan KRR, eds. Clinician's guide to psychiatric care. NewYork, USA: Oxford University Press, 2009: 51.

70 Bohn P, Monica S C. Mnemonic screening device for generalized anxiety disorder. Am J Psychiatry 2000;157:837.

71 Seitz DP. Screening mnemonic for generalized anxiety disorder. Can Fam Physician 2005;51:340-2.

72 Schnieden V. Introduction Mnemonics. In: Every good boy deserves Fudge: the book of mnemonic devices. New York, USA: Penguin Group Inc, 1999: 250-6.

73 Coupland NJ. Worry warts have generalized anxiety disorder. Can J Psychiatry 2002;47:197.

74 Khouzam HR. A simple mnemonic for the diagnostic criteria for post-traumatic stress disorder. West J Med 2001;174:424.

75 Napoli JC. Mnemonic possession. Current Psychiatry 2009;8:5.

76 Bernadino M, Nelson KJ. Fight to remember PTSD. Current Psychiatry 2017;16:17.

77 Wiseman EJ. Conversion mnemonic. Br J Psychiatry 1993;162:272.

78 Short D, Fears E. In: Kilgus MD, Rea WS, eds. Essential Psychopathology Casebook. New York, USA: W.W. Norton \& Company 2014:400-11.

79 Skjodt NM. Approach to outpatient management of adult sleep apnea. Can Fam Physician 2008;54:1408-12.

80 Rogers PT. Psychiatry. In: The medical student's quide to top board scores. Louisville, KY: Innovative Publishing \& Graphics, 1992: 79.

81 Chung F, Yegneswaran B, Liao P, et al. Stop questionnaire: a tool to screen patients for obstructive sleep apnea. Anesthesiology 2008:108:812-21.

82 Niazi S, Auger RR, Hurwitz TD. An overview of restless leg syndrome for the mental health professional. Psychiatr Ann 2015;45:35-40.

83 Fittestsurvival. Conduct disorder diagnosis, 2010. Available: http:// www.rxpgonline.com/medicalmnemonic911997.html

84 Levounis P. The wise know: decline tender Loving care and respect silver hair. Acad Psychiatry 2015;39:235.

85 CASAColumbia. Overview of addiction medicine for primary care [PowerPoint presentation]. Available: http://www.casacolumbia.org/ sites/default/files/files/Overview-of-addiction-medicine-for-primarycare.pdf [Accessed 30 Aug 2019].

86 Bogenschutz MP, Quinn DK. Acronyms for substance use disorders. $J$ Clin Psychiatry 2001;62:474-5.

87 Nordstrom BR, Levin FR. Substance Abuse: Cannabis-Related Disorders. In: Psychiatry. 3rd edn. West Sussex, England: John Wiley \& Sons, Ltd, 2008: 1045.

88 Neugroschl J, Hoblyn J, del Castillo C, et al. Alcoholism. In: Blueprints Notes \& Cases: Behavioral science and epidemiology. Massachusetts, USA: Blackwell Publishing 2004:123.
89 Krikke EH. Mnemonic acronym for DSM addiction criteria most helpful. Can Fam Physician 1998;44:33-4.

90 Mall SK, Mall GD. Drink two 6 pack clarifies substance use. Current Psychiatry 2009;8:66.

91 Nicholson T. psychiatry. in: mnemonics for MRCP. Cheshire, England: Pastest LTD 2006:103.

92 Barber W. Substance Use Disorders. In: Gliatto MF, Caroff SN, Kaiser R, eds. Concise guide to psychiatry for primary care practitioners. Washington, DC, USA: American Psychiatric Press, 1999: 50.

93 Highlights of Changes from DSM IV to DSM 5. Diagnostic and statistical manual of mental disorders: DSM-5. 815. 5th edn. Washington, DC: American Psychiatric Association, 2013.

94 Pinkofsky HB, Reeves RR. Mnemonics for DSM-IV substancerelated disorders. Gen Hosp Psychiatry 1998;20:368-70.

95 Khouzam HR. The Geriatric patient. In: Khouzam HR, Tan DT, Gill TS, eds. Handbook of emergency psychiatry E-Book. Philadelphia, USA: Mosby Elsevier Inc, 2007: 307-99.

96 Negi R, Delirium kounnisVChew-Graham CA, Ray M, eds. Mental health and older people: a guide for primary care practitioners. 167. Switzerland: Springer International Publishing, 2016.

97 Yousaf S, Chaudhry MA. Psychiatry. in: mnemonics for medical undergraduates. Cheshire, USA: Pastest Ltd, 2006: 188.

98 Pinkofsky HB. Mnemonics for DSM-IV personality disorders. Psychiatr Serv 1997;48:1197-8.

99 Healy C. Session 3. in: understanding your borderline personality disorder: a workbook. West Sussex, England: JohnWiley and Sons Ltd, 2008: 26.

100 Mahari AJ. What Is Borderline Personality Disorder? In: The legacy of abandonment in borderline personality disorder. Ontario, Canada: Phoenix Rising Publications, 2006: 12-31.

101 Senger HL. Borderline mnemonic. Am J Psychiatry 1997;154:1321.

102 Powers AD, Rustagi PK. Mnemonic device for criteria for borderline personality disorder. Am J Psychiatry 1989;146:1517.

103 Larson EW. Criticism of mnemonic device. Am J Psychiatry 1990;147:963-4.

104 Roth LS. 'DARE' to spot borderline personality disorder. Current Psychiatry 2007;6:112.

105 Kim SI, Swanson TA, Caplan JP. Underground clinical vignettes step 2: psychiatry. 130. 4th edn. Philadelphia, USA: Lippincott Williams \& Wilkins, 2007

106 Frank C, Pari G, Rossiter JP. Approach to diagnosis of Parkinson disease. Can Fam Physician 2006;52:862-8.

107 Christensen RD. Identify neuroleptic malignant syndrome with fever Current Psychiatry 2005;4:102.

108 Mannan I, Cheung V, Grout C, et al. Neurology. In: Dias A, Beck E, eds. Mrcp Part 1: 400 BOFs. 212. London, UK: JP Medical Ltd, 2013.

109 Berber MJ. FINISH: remembering the discontinuation syndrome. flulike symptoms, insomnia, nausea, imbalance, sensory disturbances, and Hyperarousal (anxiety/agitation). J Clin Psychiatry 1998;59:255.

110 McPherson F. Introduction to mnemonics. In: Mnemonics for study. 2nd edn. Wellington, New Zealand: Wayz Press, 2018: 1-10.

111 Keshavan MS. Mnemonics for DSM-IV. Part I. diagnostic criteria and psychiatric assessments. Asian J Psychiatr 2009;2:117-8.

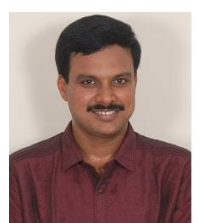

Dr Pavan Kumar kadiyala obtained an MBBS degree from Government Medical College, Guntur, Andhra Pradesh in India in 2009, and completed the post-graduation program in psychiatry from Father Muller Medical College, Mangalore, Karnataka in India in 2014. He is now working as an associate professor at the Department of Psychiatry in ASR Academy of Medical Sciences, Eluru in India. His research interests include teaching methods for post-graduates in psychiatry and geriatric psychiatry. 
Correction: Mnemonics for diagnostic criteria of DSM V mental disorders: a scoping review

Kadiyala PK. Mnemonics for diagnostic criteria of DSM V mental disorders: a scoping review. General Psychiatry 2020;33:e100109. doi: 10.1136/gpsych-2019-100109.

In this paper, all instances of 'DSM V' should be written as 'DSM 5'.

\section{(2) \\ OPEN ACCESS}

Open access This is an open access article distributed in accordance with the Creative Commons Attribution Non Commercial (CC BY-NC 4.0) license, which permits others to distribute, remix, adapt, build upon this work non-commercially, and license their derivative works on different terms, provided the original work is properly cited, appropriate credit is given, any changes made indicated, and the use is non-commercial. See: http://creativecommons.org/licenses/by-nc/4.0/.

(c) Author(s) (or their employer(s)) 2020. Re-use permitted under CC BY-NC. No commercial re-use. See rights and permissions. Published by BMJ.

General Psychiatry 2020;33:e100109corr1. doi:10.1136/gpsych-2019-100109corr1

(D) Check for updates 